\title{
PENGARUH KETIDAK TEPATAN PENYAMPAIAN SURAT PEMBERITAHUAN (SPT)-MASA TERHADAP PENERIMAAN PAJAK PENGHASILAN (PPH)PASAL 21 PADA KANTOR PELAYANAN PAJAK (KKP) BENGKULU
}

(Survei Pada Wajib Pajak Di Kecamatan Sungai Serut Kota Bengkulu)

Iprianto dan Tarmidi

Dosen Fakultas Ekonomi Universitas Muhammadiyah Bengkulu

\begin{abstract}
ABSTRAK
Dalam mewujudkan harapan pemerintah terhadap efektifnya sektor perpajakan menunjang pembiayaan pembangunan, pemerintah terlebih dahulu harus menyempurnakan per undang-undangan perpajakan dan menumbuh kembangkan kesadaran dan kepatuhan wajib pajak untuk membayar kewajiban pajaknya secara teratur dan dapat menyampaikan surat pemberitahuan (SPT)-Masa tepat waktu.

Adapun tujuan penelitian ini adalah "untuk mengetahui pengaruh ketidaktepatan penyampaian surat pemberitahuan (SPT)-Masa terhadap penerimaan pajak penghasilan ( $\mathrm{PPh})$ pasal 21.

Penelitian ini mengunakan data primer ini diperoleh melalui penyebaran kuisioner yang terdiri dari beberapa pertanyaan. Pengolahan data dilakukan menggunakan SPSS (Statistical Product And Service Solution) dan Data dianalisis menggunakan regresi linear berganda, untuk pengujian hipotesis digunakan melalui uji $\mathrm{t}$ dan uji $\mathrm{F}$.

Berdasarkan hasil penelitian dengan pengujian secara parsial, $\mathrm{H}_{1}$ yaitu ketidaktepatan penyampaian surat pemberitahuan (SPT)-Masa karena kealpaan berpengaruh signifikan dengan tingkat signifikan 0.038 dan $\mathrm{H}_{2}$ yaitu ketidaktepatan penyampaian surat pemberitahuan (SPT)-Masa karena kesengajaan berpengaruh signifikan dengan tingkat signifikan 0.019. Serta secara simultan yaitu $\mathrm{H}_{3}$ ketidaktepatan penyampaian surat pemberitahuan (SPT)-Masa karena kealpaan dan ketidaktepatan penyampaian surat pemberitahuan (SPT)-Masa karena kesengajaan mempunyai pengaruh yang signifikan terhadap penerimaan pajak penghasilan $(\mathrm{PPh})$ pasal 21 dengan tingkat signifikan 0.000 .
\end{abstract}

\section{Kata kunci: Ketidaktepatan penyampaian surat pemberitahuan (SPT)-Masa, penerimaan pajak penghasilan (PPh) pasal 21}

\section{PENDAHULUAN}

\section{Latar Belakang}

Krisis yang melanda bangsa Indonesia sejak tahun 1997 berdampak sangat luas bagi pembiayaan pembangunan. Hutang luar negeri yang menjadi andalan sumber penerimaan negara ternyata tidak dapat dijadikan andalan dalam membiayai pembanguanan, bahkan menimbulkan dampak negatif terhadap neraca pembayaran, yakni tidak seimbangnya antara hutang dengan pendapatan negara. Selain itu negara juga dihadapkan pada suatu tantangan 
yang sangat berat yaitu kewajiban untuk membayar cicilan pokok pinjaman beserta bunganya dan jatuhnya nilai tukar rupiah terhadap dollar Amerika (www.pajak.go.id 2007-2009).

Kecamatan Sungai Serut merupakan salah satu kecamatan yang ada di Kota Bengkulu yang wajib pajaknya dikatakan lamban dalam menyampaikan SPT-Masa, sehingga menimbulkan pengaruh terhadap penerimaan pajak khususnya pajak penghasilan (PPh) pasal 21.

Peranan aktif pihak fiskus dibutuhkan untuk dapat melakukan penyuluhan-penyuluhan kepada wajib pajak agar pelaksanaan perpajakan lebih efektif terutama dalam penyuluhan terhadap penyampaian surat pemberitahuan (SPT)-Masa agar tepat waktu (Daily Indonesia, 2009). Dengan demikian dapat disimpulkan, peran aktif pihak fiskus dan kesadaran dari pemotong atau pemungut pajak sangat diperlukan agar surat pemberitahuan (SPT)-Masa dapat dilakukan tepat waktu.

Dari uraian diatas, maka dapat disimpulkan bahwa kepatuhan dalam penyampaian SPTMasa sangat menentukan tercapaianya realisasi penerimaan pajak penghasilan $(\mathrm{PPh})$ pasal 21. Sedangkan agar pemotongan, penyetoran, dan pelaporan pajak atas penghasilan wajib pajak dapat dilakukan sebaik-baiknya, maka perlu ditetapkan ketentuan mengenai pelaksanaan pemotongan, penyetoran, dan pelaporan pajak penghasilan $(\mathrm{PPh})$, khususnya pajak penghasilan $(\mathrm{PPh})$ pasal 21.

Tujuan penelitian ini adalah "untuk mengetahui pengaruh ketidaktepatan penyampaian surat pemberitahuan (SPT)-Masa terhadap penerimaan pajak penghasilan (PPh) pasal 21 .

\section{METODOLOGI PENELITIAN}

\section{Jenis Penelitian}

Penelitian ini menggunakan pengujian hipotesis yang dilakukan untuk melihat pengaruh antara variabel-variabel yang akan diteliti. Variabel independen yaitu 
ketidaktepatan penyampaian surat pemberitahuan (SPT)-Masa dengan variabel dependen yaitu penerimaan pajak penghasilan $(\mathrm{PPh})$ pasal 21.

\section{Sampel Penelitian}

Metode random sampling atau sampel acak. Random sampling adalah sampel dimana peneliti "mencampur" subjek-subjek di dalam populasi sehingga semua objek dianggap sama (Arikunto, 2006:134). Sampel pada penelitian ini adalah 47 orang wajib pajak dari populasi wajib pajak penghasilan (PPh) pasal 21 di kecamatan sungai serut yang membayar pajak pada kantor pelayanan pajak (KPP) kota Bengkulu.

\section{Uji Hipotesis}

Pengujian terhadap hipotesis dapat dilakukan dengan berbagai cara, yaitu sebagai berikut: Ghozali (2005 dalam Rika, 2009:25):

\section{Uji T ( Pengaruh secara parsial )}

Uji T menunjukkan seberapa jauh pengaruh satu variabel penjelas atau independen secara individual dalam menerangkan variasi variabel dependen.

\section{Uji F ( Pengaruh secara simultan )}

Uji F menunjukkan apakah variabel independen atau bebas yang dimasukkan dalam model mempunyai pengaruh terhadap variabel dependen.

\section{HASIL YANG DICAPAI}

Berdasarkan perhitungan dengan menggunakan program SPSS diperoleh nilai setiap variabel adalah sebagai berikut :

1. Berdasarkan hasil uji t, didapat nilai signifikan p-value 0.038. Dengan demikian $0.038<$ 0.05 , artinya $\mathrm{H}_{0}$ ditolak maka variabel ketidaktepatan penyampaian surat pemberitahuan (SPT)-Masa karena kealpaan memiliki pengaruh signifikan terhadap penerimaan pajak penghasilan $(\mathrm{PPh})$ pasal 21. 
2. Berdasarkan hasil uji t, didapat nilai p-value 0.019. Dengan demikian $0.019<0.05$, artinya $\mathrm{H}_{0}$ ditolak maka variabel ketidaktepatan penyampaian surat pemberitahuan (SPT)-Masa karena kesengajaan memiliki pengaruh signifikan terhadap penerimaan pajak penghasilan $(\mathrm{PPh})$ pasal 21.

3. Berdasarkan tabel diatas, $F_{\text {hitung }} 7.09$ dengan tingkat signifikan 0.000 . Dengan demikian $0.000<0.05$ maka $\mathrm{H}_{0}$ ditolak artinya variabel ketidaktepatan penyampaian surat pemberitahuan (SPT)-Masa karena kealpaan dan ketidaktepatan penyampaian surat pemberitahuan (SPT)-Masa karena kesengajan secara bersama-sama (simultan) memiliki pengaruh yang signifikan terhadap variabel penerimaan pajak penghasilan (PPh) pasal 21.

Tabel Hasil Uji Hipotesis

\begin{tabular}{|c|c|c|}
\hline Hipotesis & Tingkat Signifikan & Konfirmasi Signifikan \\
\hline $\mathrm{H}_{1}$ & .038 & Signifikan \\
\hline $\mathrm{H}_{2}$ & .019 & Signifikan \\
\hline $\mathrm{H}_{3}$ & .000 & Signifikan \\
\hline
\end{tabular}

\section{KESIMPULAN DAN SARAN}

\section{Kesimpulan}

Berdasarkan hasil penelitian, maka kesimpulan yang dapat diambil adalah:

1. Berdasarkan hasil analisis statistik, maka diketahui bahwa secara parsial ketidaktepatan penyampaian surat pemberitahuan (SPT)-Masa karena kealpaan $\left(\mathrm{H}_{1}\right)$ memiliki pengaruh signifikan terhadap penerimaan pajak penghasilan $(\mathrm{PPh})$ pasal 21.

2. Berdasarkan hasil analisis statistik, maka diketahui bahwa secara parsial ketidaktepatan penyampaian surat pemberitahuan (SPT)-Masa karena kesengajaan $\left(\mathrm{H}_{2}\right)$ berpengaruh signifikan terhadap penerimaan pajak penghasilan $(\mathrm{PPh})$ pasal 21. 
3. Berdasarkan hasil analisis statistik, maka diketahui bahwa secara simultan (н3) ketidaktepatan penyampaian surat pemberitahuan (SPT)-Masa karena kealpan dan ketidaktepatan penyampaian surat pemberitahuan (SPT)-Masa karena kesengajaan memiliki pengaruh yang signifikan.

\section{Saran}

1. Perlu adanya peningkatan pengawasan dari pihak fiskus maupun kantor pelayanan pajak (KPP) terhadap ketidaktepatan dalam penyampaian surat pemberitahuan (SPT)-Masa, serta memberikan sanksi yang tegas untuk keterlambatan penyampaian surat pemberitahuan (SPT)-Masa baik itu karena kealpaan maupun kesengajaan.

2. Bagi wajib pajak hasil penelitian ini dapat dijadikan pedoman dan acuan untuk melakukan penyampaian surat pemberitahuan (SPT)-Masa tepat pada waktunya.

\section{DAFTAR PUSTAKA}

Arfan, Ikhsan dan muhammad ishak. 2005. Akuntansi keperilakuan. Jakarta: Salemba empat.

Departemen Pendidikan dan kebudayaan. 2001. Kamus Besar Bahasa Indonesia. Edisi kedua. Jakarta. Balai Pustaka.

Ilyas dan Bruton. 2008. Perpajakan Indonesia. Jakarta : Salemba empat.

Indrianto dan Supomo. 2002. Metodologi Penelitian bisnis Untuk Akuntansi dan Manajemen. Edisi pertama. Yogyakarta: BPFE.

Imam Ghozali. 2006. Analisis Multivariate Lanjutan dengan Program SPSS. Edisi 1 semarang : Badan Penerbitan Universitas Diponogoro.

Mardiasmo. 2009. Perpajakan, edisi revisi 2009. Yogyakarta : CV. Andi Offset.

Mardiasmo. 2010 . Perpajakan, edisi revisi 2010. Yogyakarta : CV. Andi Offset.

Martono. 2010. Metode Penelitian Kuantitatif. Jakarta. PT. RajaGrafindo Persada. 
Waluyo. 2010. Perpajakan Indonesia : Pembahasan sesuai dengan ketentuan pelaksanaan perundang-undangan perpajakan terbaru, Buku 2. Jakarta : Penerbit Salemba Empat.

Robert Konopaske. 2007. Perilaku dan Organisasi. Bandung: Erlangga.

Siti Resmi. 2005. Perpajakan teori dan kasus. Jakarta : Salemba empat.

Suandi Erli. 2006. Perpajakan. Jakarta : Salemba empat.

Sugiyono. 2008. Metodologi Penelitian Bisnis. Bandung : Alfa Beta.

Suharsimi Arikunto. 2006. Manajemen penelitian. Jakarta : PT. Rineke Cipta. 